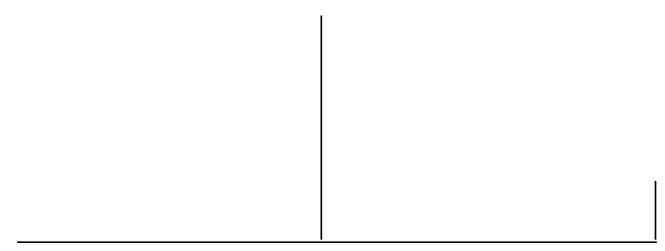

Rev. Latinoam. Psicopat. Fund., VI, 1, 53-75

\title{
O diagnóstico transdisciplinar em psicopatologia
}

\author{
Isac Nikos Iribarry
}

Este artigo é uma apresentação do Diagnóstico Transdisciplinar em Psicopatologia (DTP). O DTP é um dispositivo cuja finalidade é incentivar e sistematizar a aproximação e o diálogo entre a psiquiatria e a psicanálise. O DTP pretende conjugar os esforços dos dispositivos técnicos da psiquiatria e da psicanálise. Tais dispositivos (apresentação psiquiátrica de pacientes, DSM-IV, apresentação psicanalítica de pacientes e escuta psicanalítica) são colocados em uma situação de diálogo e colaboração para implementação do DTP.

Palavras-chave: Diagnóstico, transdisciplinar, psicopatologia 
Apesar das críticas sofridas tanto pela psiquiatria quanto pela psicanálise, o trabalho com o psicopatológico na clínica da psicose segue seu caminho na rede de saúde pública. Isso porque no cotidiano da rede de saúde pública não há um espaço privilegiado para discussão de problemas quanto às orientações técnicas da psiquiatria e da psicanálise. A comparação entre psiquiatria e psicanálise não é de muita utilidade, já que as crescentes demandas de pacientes que procuram os serviços em razão de seus sofrimentos psíquicos exigem que os profissionais, psiquiatras e psicanalistas, busquem antes o diálogo e a cooperação do que o debate sobre eventuais polêmicas entre suas áreas de conhecimento. Podemos dizer que o diálogo e a cooperação se instauram numa perspectiva prática quando um determinado caso exige cuidados que envolvem a conjugação dos esforços de uma psiquiatria psicodinâmica, que concilie uma meditação sobre a abordagem psicofarmacológica, acompanhada de uma abordagem psicoterápica, com os esforços de uma clínica psicanalítica.

O Diagnóstico Transdisciplinar em Psicopatologia - DTP, é uma experiência. Uma experiência que resulta de uma aproximação inevitável e necessária, ainda que não suficiente: a aproximação entre a psiquiatria e a psicanálise. O DTP se coloca numa perspectiva dialógica. Incentiva o encontro daqueles dispositivos que estão na ordem do dia quando a psiquiatria e a psicanálise apresentam suas intervenções para o psicopatológico da clínica da psicose. O DSM-IV, a apresentação psiquiátrica do paciente, a escuta do significante e a apresentação psicanalítica de paciente são os dispositivos convidados a uma situação de diálogo na experiência do DTP. O DTP é uma experiência em que o diálogo entre os dispositivos da psiquiatria e da psicanálise estão focalizados no domínio da clínica da psicose e sua psicopatologia. Sendo assim, para implementação do DTP, é necessário estabelecer uma delimitação do ponto de vista clínico. Nossa proposição começa com a aproximação dos dispositivos das clínicas psiquiátrica e psicanalítica (DSM-IV e escuta) e de um diálogo firmado pela conjugação dos esforços da apresentação psiquiátrica de paciente e da apresentação psicanalítica de paciente. Mas é necessário orientar o trabalho numa direção clínica específica. A idéia é preparar uma apresentação do DTP a partir do encontro da psiquiatria e da psicanálise. Convém salientar, ademais, que o diálogo entre a psiquiatria e a psicanálise não exclui a participação de outras disciplinas e que o foco que irá se estabelecer nos trabalhos da rede de saúde pública, 


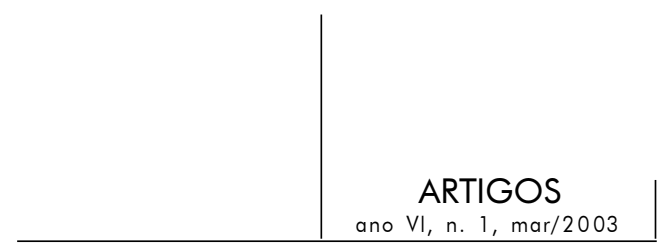

em sua área dedicada à chamada saúde mental, é uma estratégia necessária para evitar uma dispersão ou mesmo uma pretensão megalomaníaca de submeter à experiência, hic et nunc, toda a ampla gama de fatores envolvidos no trabalho com o psicopatológico. Futuramente, convém lembrar, o modelo em que se baseia o DTP, isto é, o diagnóstico do psicopatológico em situação de transdisciplinaridade, poderá servir às aproximações dialógicas entre outras disciplinas e áreas do conhecimento.

\section{Avaliação, diagnóstico e tratamento em psiquiatria e psicanálise}

Uma avaliação na clínica psiquiátrica é um conjunto de exames. É preciso examinar as condições somáticas, neurológicas e psiquiátricas do sujeito que se apresenta. A esse conjunto de exames é acrescentada uma observação clínica (Ey, Bernard \& Brisset, 1990). Nem sempre, é verdade, se pode reunir esse conjunto de exames. Tampouco a rotina psiquiátrica envolverá tais procedimentos, já que as idiossincrasias de cada contexto em que ela se estabelece delimitam diversos modos de realização desses exames. Sobretudo no sistema público de saúde, o qual nem sempre é dotado das condições ideais em termos de espaço físico, instrumentos e recursos humanos. Todavia, é fato que essa etapa em que se examina o paciente que busca auxílio psiquiátrico resulta em um diagnóstico ao qual se acrescenta um tratamento. Depois de ser observado em sua semiologia, e então classificado no amplo espectro nosográfico dos chamados transtornos comportamentais, o paciente recebe uma orientação de duas claves. De um lado, o medicamento, dado pela orientação psicofarmacológica; de outro lado, algumas vezes, a orientação, por assim dizer, espiritual, a qual se estabelece por meio das possibilidades dele freqüentar um ambulatório e falar de seu sofrimento.

Na clínica psicanalítica, uma avaliação é sempre um tempo de escuta. Mas não de uma escuta ordinária, do puro efeito sensorial de ouvir, mas de uma escuta que se deixa dirigir pelo olhar. Uma escuta que permanece atenta à teoria psicanalítica sobre o psicopatológico e também ao significante articulado pela fala do paciente. De modo simplificado, é claro, podemos dizer que a este tempo fundamental de escuta se acrescenta um segundo: o do diagnóstico. Daí se procura observar, evitando uma relação de compreensão, a estrutura psíquica e o endereçamento transferencial do paciente. Isso cria condições para que uma outra compreensão se dê: uma compreensão desligada de qualquer altruísmo ou afetividade, isto é, uma compreensão lógica do sofrimento narrado pelo paciente. O tratamento é o terceiro tempo, o tempo de concluir, ou seja, o momento em que uma direção - no sentido vetorial - é apontada para que o trabalho de análise 


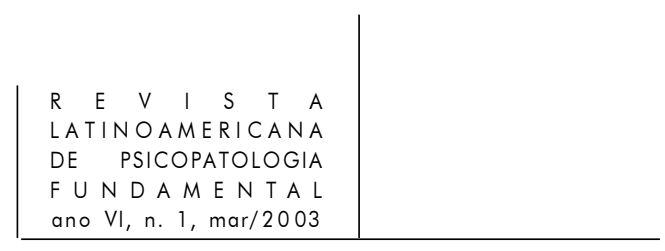

comece e prossiga (Lacan, 1998). É preciso, no entanto, entender que novamente estamos apresentando as condições ideais para os procedimentos da clínica psicanalítica. Porém, no caso da psicanálise, não são os fatores ligados ao espaço físico e aos instrumentos, mas antes aquilo que diz respeito ao próprio analista enquanto recurso humano que deve ser sublinhado. Suas dificuldades, entretanto, não serão objeto de nossa reflexão nesse momento. Tampouco vamos discutir o problema da dispersão da psicanálise em diversos estilos clínicos. Basta lembrar que tais idiossincrasias existem e não podem ser desconsideradas.

\section{Psicopatológico}

Assim, passamos à referência que a pesquisa psicanalítica freudiana e lacaniana nos permite situar sobre o psicopatológico. Evitamos com isso que nossa experiência se disperse. Não vamos nos deter, entretanto, em longas considerações sobre o psicopatológico. É suficiente, neste momento, apresentar nossa adesão às idéias de Berlinck (2000) e Caon (1994). O primeiro define o psicopatológico como um discurso, no sentido de uma narrativa, sobre as paixões da alma. O segundo insiste sobre a duplicidade de uma constituição psíquica inevitável: estamos submetidos a um sofrimento quando ingressamos no simbólico - aceder à linguagem é uma experiência de corte e produz dor -, e da estrutura que conservamos dessa experiência primordial irá restar uma expressão em cada uma de nossas ações. Mas o psicopatológico estudado pela clínica psiquiátrica, como vimos acima, está bem situado pelos procedimentos envolvidos em sua avaliação, diagnóstico e tratamento. $\mathrm{O}$ mesmo não se pode dizer daquele psicopatológico a que se dedica a clínica psicanalítica, já que sua origem é, muitas vezes, uma decorrência da experiência de alunos estagiários advindos de cursos de graduação em psicologia, que depois escolhem trabalhar como psicanalistas. O que nos conduz à necessidade de pensar em uma clínica psicológica de aspiração psicanalítica.

\section{A clínica psicológica e sua aspiração psicanalítica}

Quando falamos de uma clínica psicológica de aspiração psicanalítica, estamos oferecendo uma tentativa de solução provisória para o problema da clínica psicológica em que se formam alunos do curso de psicologia, mas que pautam suas primeiras atividades como clínicos, desde o estágio até os primeiros exercícios profissionais, sob a égide do conhecimento psicanalítico. O que 


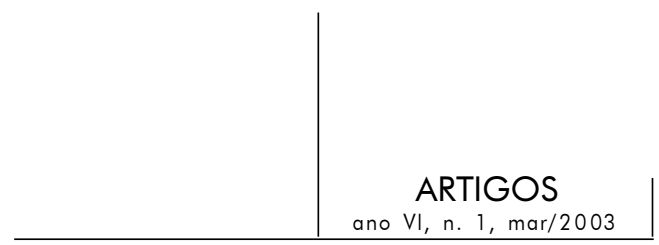

também se observa no trabalho da área de saúde pública onde apesar, dos serviços serem realizados como atendimentos psicológicos, o que se observa é um trabalho de cunho psicanalítico. Nesse sentido, é possível pensar numa clínica miscigenada, pois o saber psicanalítico se mistura às orientações psicológicas em razão de muitos futuros psicanalistas fazerem primeiro a experiência de uma graduação em psicologia. O que nos interessa, no entanto, é salientar que quando falamos de clínica psicanalítica ao longo desse trabalho, estamos cientes desse problema, ainda que não o coloquemos em discussão. E que a clínica psicanalítica que será evocada ao longo do trabalho está especialmente situada nessa perspectiva.

Não havendo literatura específica sobre essa transição, façamos, por nossa conta e risco, algumas considerações. Podemos ouvir da boca dos profissionais, e mesmo dos estagiários de psicologia clínica, que a clínica psicanalítica é um momento a ser alcançado através de um amadurecimento profissional. Tal amadurecimento envolve, como etapa crucial, o próprio estágio na clínica. Isso sem falar dos problemas ligados às querelas sobre a formação do psicanalista e sua institucionalização. Isso não está contemplado por nossa experiência. Iremos nos deter precisamente no fato de que aqueles que buscam o exercício clínico da psicanálise são muitas vezes psicólogos que investem em suas análises pessoais e mergulham nos seminários universitários e institucionais de formação, além de receberem pacientes e supervisionarem com psicanalistas de maior experiência. Entre esses profissionais iremos encontrar aqueles que iniciam sua formação nos estágios de psicologia clínica e procuram direcionar sua escuta por meio de uma práxis ainda incipiente e preliminar de uma aprendizagem que irá se descobrir permanente e inevitável.

Outro fato que nos impõe esta delimitação é que os profissionais da área de saúde mental são auxiliados por alunos ainda em fase de conclusão do curso de psicologia. Todavia, suas perspectivas de uma identidade profissional estarão ainda em construção e no lugar do jargão que enfatiza a famigerada "orientação psicanalítica", optamos pela palavra "aspiração", que parece traduzir melhor o que há de ético na escolha em questão. Quem aspira à clínica psicanalítica não pode desejar senão que seu paciente se analise, mas isso, como sabemos, não é assim tão simples. É necessário um percurso para que o aspirante encontre estilo e experiência para que sua clínica seja uma clínica de ato psicanalítico. Talvez Roudinesco (1994; 2000) possa servir-nos de justificativa quando menciona uma nova estética para o psicanalista. Isto é, aquele que já não veste ternos trespassados, mas sim calça jeans e tênis, tomando um ônibus até a periferia, onde divide o trabalho do consultório particular com postos de saúde, escolas e centros comunitários. Também os alunos que realizam estágios de psicologia 


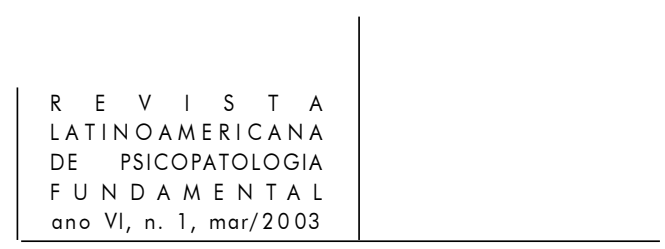

clínica, aspirando à legitimidade de uma clínica psicanalítica, são muitas vezes os psicanalistas que amanhã definirão os destinos desta clínica que sobrevive apesar dos esforços de uma ciência triunfante que procura reduzir o psíquico a um objeto-alvo exclusivo da psicofarmacologia, sendo preferível o silêncio a ter de se buscar uma linguagem, uma narrativa sobre o sofrimento, pois esta é sempre motivo de angústia e vergonha.

\section{A clínica médico-psiquiátrica como clínica fenomenológica}

A chamada clínica médico-psiquiátrica pode ser colocada, do ponto de vista de sua rotina, sob a égide da fenomenologia husserliana. No trabalho clínico do psiquiatra, ele é movido, quando está diante do paciente, por uma consciência doadora de sentido para o mundo e para as coisas do mundo. A consciência do psiquiatra "vive" como doadora de sentido para o objeto que lhe é dado a ver. Pois não se trata de reconhecer um sujeito tomado por uma perturbação mental, mas antes de reconhecer a perturbação mental como objeto de uma intervenção. Mas para que esta intencionalidade encontre desfecho é preciso que o psiquiatra seja conduzido por uma evidência que é o resultado da unidade sintética entre sua mente e o objeto focalizado. Esta evidência é uma evidência apodítica. A evidência apodítica está baseada em uma intuição acerca do objeto focalizado. No caso do psiquiatra, sua intuição é originária, pois está diante de um sujeito em que se destaca uma doença (objeto) que está presente em sua corporeidade e, por isso, o objeto-doença é um objeto intuído real (Husserl, 1960). É importante, no entanto, salientar nossa opção por uma clínica médico-psiquiátrica denominada psicodinâmica. A psiquiatria dinâmica está interessada em valorizar os aspectos psíquicos desvinculados de uma organogênese radical e direcionada a uma abordagem exclusiva e unicamente psicofarmacológica. Assim, é na direção de uma rotina que coloca o psiquiatra diante de um sujeito que lhe vem pedir ajuda que estabelecemos esse preâmbulo fenomenológico. Tal preâmbulo coloca em destaque a consciência como doadora de sentido para a experiência do psiquiatra.

\section{A clínica psicanalítica como clínica metapsicológica}

Entender a clínica psicanalítica como uma clínica metapsicológica exige, em primeiro lugar, que expliquemos o que é metapsicologia. Metapsicologia é 


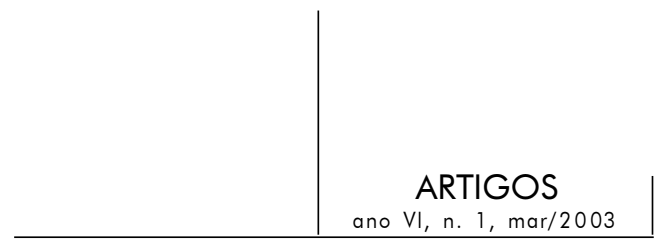

um campo de conhecimentos psicanalíticos que vai da vivência de uma experiência à elaboração de uma ficção teórica. Da ficção teórica se vai à alteridade e, depois disso, se retorna à experiência. Nesse processo, um saber pode ser construído e, assim, quando o pesquisador retornar à experiência poderá modificar e transformar radicalmente o sentido dela (Iribarry, 2000). O processo descrito acima envolve tanto a perspectiva do analista quanto a do analisante. $\mathrm{O}$ analista modifica sua experiência a partir das ficções teóricas que elabora e submete às alteridades diversas de seu trabalho (analista de controle, colegas e colaboradores, outros pesquisadores), e o analisante a modifica por meio da própria experiência de análise que nada mais é do que uma vivência em que ficções particulares são colocadas à prova. Ora, isto posto, podemos entender a clínica psicanalítica como uma clínica metapsicológica, já que ela é lugar de produção de metapsicologia (Garcia-Roza, 1992).

\section{A clínica da psicose}

O DTP é uma proposição que envolve a aproximação entre a clínica psiquiátrica e a clínica psicanalítica, bem como de seus respectivos dispositivos de apresentação de pacientes e apresentação psicanalítica de pacientes. Contudo, a formulação preliminar do DTP deve estabelecer um foco sobre a clínica da psicose. A proposição do DTP reflete a necessidade de aproximar os dispositivos da psiquiatria e da psicanálise, DSM-IV e escuta, para a realização de um trabalho com o psicopatológico, especialmente diante dos desafios apresentados pela clínica da psicose. Todavia, convém preservar o caráter fenomenológico da clínica psiquiátrica e o caráter metapsicológico da clínica psicanalítica para que suas diferenças alcancem um nível de complementaridade; jamais de exclusão mútua. A consciência que "vive" como doadora de sentido e a elaboração metapsicológica se complementam à medida que aí estão reunidos os procedimentos de avaliação, diagnóstico e tratamento da psiquiatria e da psicanálise, bem como os dispositivos DSM-IV e escuta psicanalítica.

\section{A apresentação do paciente psiquiátrico}

O paciente psiquiátrico é comumente apresentado na reunião clínica da equipe. Sua apresentação reúne o testemunho de todos aqueles profissionais que lhe dão assistência durante uma triagem, uma internação ou um procedimento ambulatorial. Esse testemunho se organiza como um conjunto de informações 


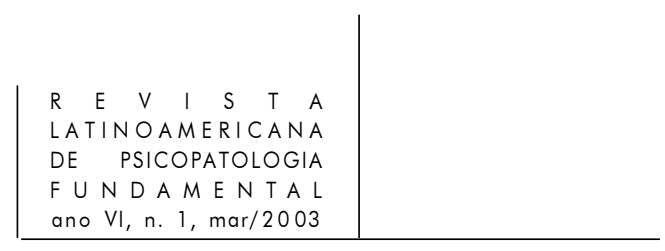

registradas (no prontuário ou papeleta, por exemplo), as quais servem para formulação e reformulação de diretrizes diagnósticas bem como para a direção do tratamento (Gabbard, 1990).

\section{A apresentação psicanalítica de pacientes}

A apresentação psicanalítica de pacientes é um dispositivo da clínica psicanalítica que se destina ao trabalho com o psicopatológico numa situação em que a assistência dada ao paciente que padece de um sofrimento psíquico é feita pelo trabalho de equipe. A apresentação psicanalítica de pacientes conta, em primeiro lugar, com o técnico apresentador do paciente. O técnico leva o paciente até o entrevistador, e a equipe compõe uma audiência, silenciosa, que ocupa o lugar do psicanalista. Segundo Bastos (1999), o paciente

... é designado por um membro ou pela equipe encarregada do seu tratamento. A entrevista the é proposta, a informação de que outras pessoas estarão presentes lhe é comunicada e seu acordo é solicitado. O psicanalista é precariamente informado sobre o caso. Via de regra, o psiquiatra leva a seu conhecimento algum dado do problema que suscitou a indicação do paciente para a apresentação ou algum elemento da história de sua doença. O paciente é conduzido à sala por seu psiquiatra, encontrando a assistência já instalada. Ele é recebido pelo psicanalista, convidado a sentar-se diante deste e a falar de si, de seu estado e das razões que o levaram à hospitalização. A audiência, o psiquiatra e a equipe não intervêm em momento algum. A entrevista dura de uma hora e meia a duas horas. A assistência pode fazer anotações. O psicanalista nunca as faz. Terminada a apresentação, o psiquiatra (ou algum membro da equipe) retira-se com o paciente, voltando sozinho logo depois. Tem início a discussão do caso sob a condução do psicanalista, com a participação do psiquiatra, que é chamado a fornecer informações adicionais ou esclarecer pontos que permaneceram obscuros. A platéia deixa sua posição de espectadora, podendo tomar parte ativa no debate. (p. 6)

Todavia, não deixaremos de mencionar que o dispositivo da apresentação psicanalítica de pacientes coloca em jogo o reconhecimento da cidadania do paciente. Comumente excluído, o paciente afetado pelo psicopatológico da psicose tem sua cidadania não reconhecida em razão de ser tomado por sua doença, a qual fica etiquetada em sua alma a ponto de ele próprio realizar um discurso, apoiado em classificações de manuais, sobre si mesmo enquanto paciente de uma enfermidade mental. A apresentação psicanalítica de pacientes devolve o sujeito ao lugar de sua singularidade histórica e exige que o paciente encontre seu lugar 


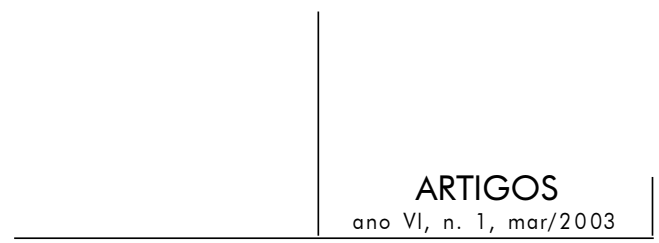

por meio de uma palavra antes negada, mas agora tomada em sua radicalidade essencial: o nome próprio (Iribarry, 2002).

\section{A apresentação do paciente no DTP}

A apresentação do paciente, buscada pelo DTP, é um resultado do esforço compartilhado entre psiquiatras e psicanalistas e, naturalmente, dos demais membros de uma equipe de trabalho com o psicopatológico da clínica da psicose. Todavia, as fronteiras entre o conhecimento e o saber das diferentes áreas são preservadas ao mesmo tempo que se interpenetram e, uma vez ampliadas, aumentam também o alcance do diagnóstico. A apresentação do paciente psiquiátrico contribui para uma compreensão do psicopatológico através da confrontação entre a experiência dos profissionais e as informações oriundas da literatura e das pesquisas mais recentes. A apresentação psicanalítica do paciente resgata-lhe a palavra e ele é aquele que ensina, em cima do lance, algo a respeito de seu sofrimento. Sua narrativa na apresentação psicanalítica pode ser colocada ao lado dos achados da apresentação psiquiátrica para um aprimoramento das diretrizes diagnósticas e da direção de tratamento. Assim, DSM-IV e escuta psicanalítica aparecem como dispositivos que não competem entre si, mas cooperam para um aprimoramento do diagnóstico do psicopatológico em situação de transdisciplinaridade. (Ibid)

\section{O diagnóstico transdisciplinar em psicopatologia}

A palavra diagnóstico vem do grego diagnostikós e está relacionada à diagnose. Diagnose vem do grego diágnosis e possui acepções ligadas à história natural e à botânica. Em história natural a diagnose envolve uma descrição minuciosa do animal ou da planta, realizada pelo seu classificador por meio de termos em latim. Na botânica, a diagnose serve para realizar uma descrição abreviada de uma família, gênero ou espécie. Por outro lado, a palavra diagnóstico está, hoje em dia, especialmente associada à medicina. Nesse âmbito, diagnóstico significa o conhecimento ou a determinação de uma doença pelos sintomas ou sinais mediante exames diversos (radiológicos, laboratoriais, etc.). O diagnóstico na medicina cumpre a função de uma visão sobre um estado somático ou mental. No caso de uma fratura exposta, por exemplo, o médico vê a fratura e a diagnostica evocando simultaneamente o tratamento, que vai de sua correção ao 


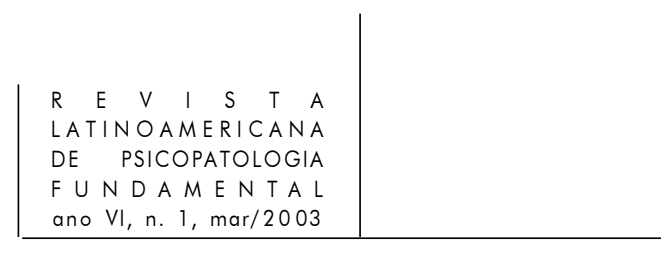

engessamento. Em geral, a medicina estabelece o diagnóstico a partir dessa visão sobre um estado somático ou mental, independente da especialidade em questão. $\mathrm{Na}$ clínica médico-psiquiátrica, como vimos acima e veremos mais adiante, o diagnóstico é uma antecipação dada pelos manuais de classificação das doenças mentais. Coisa diversa se passa na clínica psicanalítica. Ela é uma clínica em que três tempos se dinamizam e se articulam para que a experiência do diagnóstico tenha lugar: um tempo de olhar, um tempo de compreender e um tempo de concluir, nos quais o diagnóstico fica suspenso até o ponto em que o próprio paciente o tenha formulado através de sua narrativa de uma experiência sofredora. Como nos diz Berlinck (2000), o diagnóstico dos manuais é uma versão prèt-aporter do psicopatológico, enquanto na clínica psicanalítica a investigação diagnóstica é considerada alta costura.

Embora esteja associada exclusivamente à medicina, a palavra psicopatologia admite mais do que a significação sugerida pelo dicionário. Ela não fica restrita ao domínio de estudo, descrição, classificação e evolução dos mecanismos das psicopatias. Naquilo que está sob nosso foco de investigação, vamos observar uma psicopatologia de que se servem médicos psiquiatras e psicanalistas. Tal psicopatologia está no conjunto da psicopatologia geral e se distingue por sua especificidade à medida que se ocupa das psicopatologias psíquicas. Ou que precisamente se manifestam nesse domínio. Vamos chamá-la de psicopatologia dos manuais. Tanto nas residências psiquiátricas quanto nos estágios de psicologia clínica, encontramos manuais de psicopatologia servindo como referência às práticas dos alunos bem como ao trabalho dos supervisores. Como veremos adiante, o DSM-IV e a CID-10 são manuais básicos nesse âmbito e, evidentemente, não podemos esquecer de alguns usos que se faz das obras de Freud e Lacan em que se observa um certo mimetismo do texto de modo que também sirvam como manuais de psicopatologia, ainda que psicanalítica. Assim sendo, a psicopatologia dos manuais está inserida na tradição da psicopatologia geral e deve a Jaspers e Kraepelin, como veremos adiante, sua disseminação nos contextos de trabalho com o psicopatológico enquanto sofrimento psíquico. Nossa concepção de psicopatologia, no entanto, seguirá as posições de Caon (1994) e Berlinck (2000) em termos de to pathei mathos e de uma psicopatologia fundamental, respectivamente. Ademais, o próprio autor deste trabalho deverá realizar sua apropriação de tais posições de modo a apresentar sua posição para o diagnóstico transdisciplinar. Para Caon (1994), o psicopatológico suscita a possibilidade de uma experiência de aprendizagem pelo sofrimento. É o to pathei mathos, aprender com e pelo sofrimento. Para o autor é necessário, além disso, não desmanicomializar apenas o sujeito institucionalizado em hospícios, mas também os profissionais que o assistem, pois estes estão internados nos manuais de psicopatologia. Para Berlinck (2000), o termo pathos traz a idéia de paixão e 


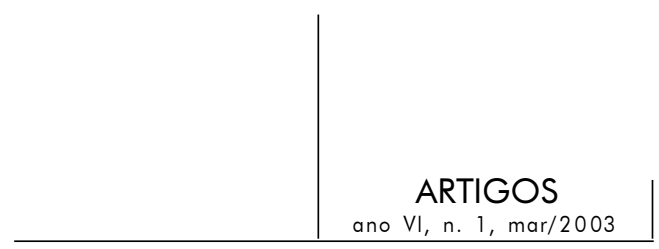

passividade e sua proposição acerca de uma psicopatologia fundamental se interessa por um sujeito trágico cujas ações lhe escapam e o colocam numa posição de paciente desta realidade trágica. $O$ autor salienta ainda que se pode tirar proveito do pathos, já que se pode transformá-lo em experiência. Berlinck (Ibid.) situa o pathos como o vivido que se pode tornar objeto de uma experiência psicopatologia quer dizer um sofrimento, uma passividade da ordem da paixão, que porta em si mesmo a possibilidade de um ensinamento interno que não ocorre sem a presença da alteridade, pois a razão é insuficiente para evocá-lo como conseqüência. A psicopatologia fundamental está disposta a escutar um sujeito portador de uma única voz que fala do pathos. Sendo sempre objeto da transferência, isto é, de um discurso que serve como narrativa do sofrimento, das paixões, daquela passividade que vem de longe e de fora e brota no corpo. Essa narrativa supõe um interlocutor, uma alteridade capaz de transformá-la em experiência, gerando a possibilidade de pensar aquilo que ainda não foi pensado. A psicopatologia fundamental se distingue, portanto, da posição de uma psicopatologia geral. Esta última é um discurso sobre as doenças, sobre as formas corporais-discursivas que assumem o pathos. A primeira quer suscitar uma experiência compartilhada pelo sujeito que padece de um sofrimento.

Nesse sentido, o DTP deve alargar as possibilidades de compreensão do psicopatológico. O transdisciplinar é tomado aqui como uma possibilidade de congregar diversas disciplinas em uma equipe de trabalho com o psicopatológico. Transdisciplinar é uma modalidade de organização de disciplinas agrupadas em que são respeitados os diferentes níveis de realidade e as diferentes lógicas de cada área de conhecimento. O diagnóstico transdisciplinar em psicopatologia deverá ser uma experiência de construção. Uma construção realizada em conjunto pelas diferentes vozes que compõem uma equipe que trabalha com diferentes escutas para o psicopatológico. Esta construção deverá recuperar a concepção de vivência (Erlebnis) resgatada por Gadamer (2000) e as noções de uma narrativa sobre o tempo presente de Ricoeur (1990).

A vivência (Erlebnis) é uma experiência em que o sujeito ainda está vivo quando algo acontece: vivenciar, para Gadamer (2000), carrega o tom da imediaticidade e se separa daquilo que se pensa saber. $\mathrm{O}$ que se sabe pelo outro, o que se ouve falar ou mesmo aquilo que se intui está sempre em falta da credencial da vivência própria. O vivenciado (das Erleben) será sempre o que nós vivenciamos (das Selbsterlebt). A vivência tem algo da ordem de uma aventura. Gadamer não a situa simplesmente como um episódio. Os episódios, graças a sua singularidade, não procuram por uma correlação interna e, por isso, não têm significado duradouro. Uma aventura, por outro lado, interrompe o curso costumeiro das coisas e tem uma relação positiva e significativa com essa interrupção. Na aventura, sentimos a vida com toda sua amplidão e força. Eis o fas- 


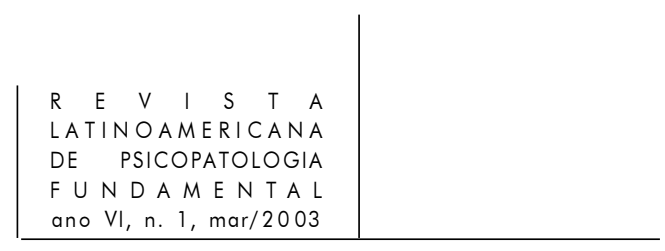

cínio trazido pela aventura: põe de lado as condicionalidades e compromissos da vida costumeira e ousa partir rumo ao que é incerto.

Ricoeur (1990) nos fala do tempo presente como uma passagem que possibilita sua medida. Assim, o tempo presente nos permite desdobrá-lo em três momentos que se interpenetram. Como se a célula do presente enquanto instante em que me encontro agora estivesse atravessada por três presentificações diferentes deste presente. Passado, presente e futuro estão incluídos no tempo presente. O passado surge como presente através da memória; o presente é a visão do próprio presente; o futuro é a espera que nos inclina à previsão. A vivência e o presente são elementos cruciais para o diagnóstico transdisciplinar em psicopatologia. Quando uma equipe dá assistência e escuta para o psicopatológico, todos os seus membros se inserem numa vivência coletiva e compartilhada. Nesta vivência, diversas áreas de conhecimento e diversas práticas organizadas a partir de diferentes saberes encontram lugar. O diagnóstico transdisciplinar é um dispositivo que se destina a tomar esta vivência como uma aventura, no sentido evocado por Gadamer (2000). O diagnóstico transdisciplinar, portanto, tem a finalidade de traduzir esta vivência da equipe junto ao paciente como uma possibilidade diagnóstica, isto é, uma construção que subverte a noção comum e fixa de um tempo presente que cristaliza e interna profissionais nas referências semiológicas e nosográficas da psiquiatria e da psicanálise. Não se trata de dispensar tais referências, mas de dar a elas uma nova articulação e priorizar um diagnóstico chamado transdisciplinar em que o tempo presente se desdobre em memória, visão e espera. A memória da experiência de cada membro da equipe e do paciente. A visão momentânea da equipe e do paciente e a espera do tempo em que o diagnóstico irá se construir na vivência da equipe e do paciente durante sua assistência e tratamento.

\section{O aparelho óptico}

O aparelho óptico é uma figura extraída da posição de Galileu na universidade. Galileu, quando realizava suas pesquisas astronômicas, tinha o costume de convidar seus colegas a observarem os astros a partir de suas lunetas e telescópios. Galileu convidava seus colegas a vislumbrarem seu objeto a partir de seu ângulo de visão. O DTP convida psiquiatras e psicanalistas a compartilharem de seus aparelhos ópticos para visão do psicopatológico na clínica da psicose. A apresentação do paciente psiquiátrico, a apresentação psicanalítica de pacientes, o DSM-IV e a escuta psicanalítica são aparelhos ópticos que deverão reunir esforços para uma melhor compreensão do psicopatológico na clínica da 


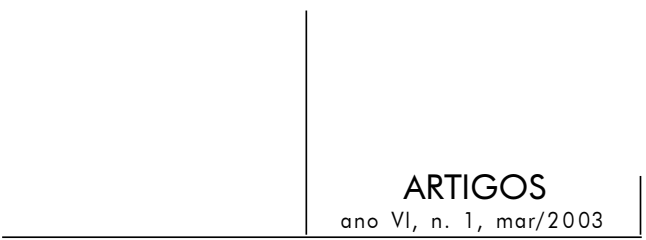

psicose. A reunião desses esforços pode acontecer por meio do diálogo entre os profissionais das duas orientações clínicas (Caon, 1998; Iribarry, 2002).

O diálogo

Toda proposição dialógica, num sentido platônico, começa pela premissa "vamos conversar sobre o quê?". Assim é no Banquete, quando Fedro sugere que Agáton e seus convivas realizem discursos como forma de elogio ao deus Eros (Platão, 2001). Da mesma forma, psiquiatras e psicanalistas podem dialogar buscando complementaridade através do compartilhamento de seus aparelhos ópticos. Essa complementaridade, no entanto, não deve ser absoluta. Como sabemos, o outro pode dizer coisas que nos faltam e isso é a constatação de que vivemos sempre na falta-a-ser. A ser preenchida, a ser redimensionada, etc. O diálogo nunca se completa. Ele é sempre interrompido e retomado em um outro momento. O diálogo é, por assim dizer, permanente. Assim, psiquiatria e psicanálise, bem como outras áreas de conhecimento, devem se manter numa perpétua situação de diálogo. E essa é uma conseqüência imediata do DTP. (Iribarry, 2002)

\section{O cuidado de Eros doente e a psicoterapia}

Como nos diz Erixímaco no Banquete, há dois tipos de Eros, dos quais o médico se ocupa. Um Eros saudável e um Eros doente. Para Erixímaco, no entanto, Eros se manifesta em um nível somático, corporal. O médico, e podemos estender a definição do diálogo platônico para o trabalho de todos os profissionais que se ocupam do sofrimento psíquico, é aquele que cuida de Eros doente. Esse cuidado é terapêutico e a psicoterapia representa uma possibilidade para esse cuidado. Não se trata de abandonar ou suspender as técnicas das clínicas psiquiátricas e psicanalíticas, mas antes de adotar o modelo da psicoterapia como uma possibilidade de assistência do paciente em atendimento na rede de saúde pública. A psicoterapia é uma modalidade de tratamento em que há um encontro entre terapeuta e paciente. Seu objetivo é criar um espaço de diálogo que deve ser libertador tanto para o terapeuta quanto para o paciente. Não se abandona o DSM-IV nem a escuta psicanalítica, porém se busca, por meio deles, uma singularidade para o caso que está sendo tratado. Essa singularidade deve prevalecer sobre o conhecimento psiquiátrico e psicanalítico, pois o paciente é 


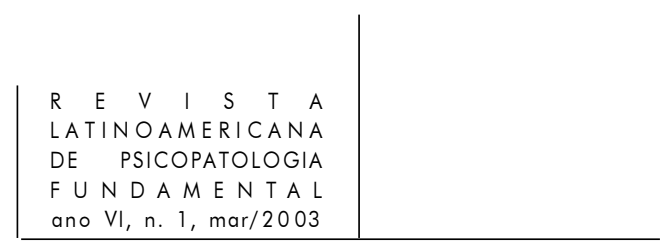

quem nos ensina algo sobre seu sofrimento. Os dispositivos técnicos de cada clínica colaboram para um melhor entendimento do caso, mas é o próprio caso que deverá questioná-los e renová-los permanentemente (Iribarry, 2002).

\section{O DTP na área de saúde mental da rede de saúde pública}

A divisa que sumariza nossa contribuição nesta reflexão é a proposição de um novo modus operandi para o trabalho das equipes que assistem o psicopatológico na rede de saúde pública. Trata-se da construção de uma proposta renovada para a abordagem dos trabalhos de avaliação, diagnóstico e tratamento de pacientes em atendimento na área de saúde mental da rede de saúde pública, a qual é realizada por profissionais que trabalham em equipe multidisciplinar. Evocamos a configuração denominada multidisciplinar pois sabemos que no atendimento previdenciário público as equipes são compostas por profissionais - técnicos - de diferentes áreas. Geralmente, nos primeiros níveis de atenção, ou seja, nos postos de saúde avançados, a equipe é pequena e constituída de um clínico geral mais um pediatra ou ginecologista. Nos postos de saúde que oferecem serviços ambulatoriais, ainda em um primeiro nível de atenção, as equipes já contam com assistentes sociais, enfermeiros, médicos de diferentes especialidades e psicólogos. Para o segundo e terceiro níveis de atenção - hospitais gerais credenciados pelo SUS e serviços especializados do setor público previdenciário - encontraremos profissionais estabelecidos em gabinetes especializados, como cardiologistas, dermatologistas, radiologistas, etc. (Iribarry, 2002). A configuração multidisciplinar é observada, em especial, no primeiro nível de atenção. Entendemos tal configuração como multidisciplinar, pois, como veremos mais adiante, o trabalho multidisciplinar envolve um sistema de nível único e objetivos múltiplos (Japiassu, 1976).

Quer isto dizer: o paciente chega para o atendimento e, após ser triado, encontra destino em uma especialidade. Somente a partir daí que, se o caso revelar dúvidas de diagnóstico e tratamento, uma equipe ambulatorial irá discutir seu tratamento numa perspectiva interdisciplinar. A proposta interdisciplinar, contudo, verticaliza um saber sobre outro e impede a geração de novos dispositivos para acolhimento das demandas. A tônica da proposta do DTP é a de difundir o espírito transdisciplinar entre os profissionais que trabalham em equipe. Cada profissional deverá trabalhar em situação de transdisciplinaridade, convidando seus colegas a vislumbrarem seu objeto a partir da luneta que lhe serve de ferramenta na observação do fenômeno abordado. Ademais, cada profissional poderá levar os problemas não resolvidos em sua área para a área do colega, a fim de 


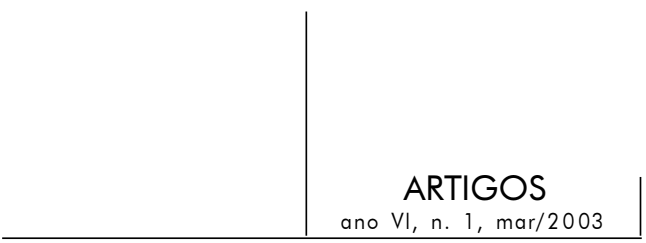

promover uma discussão e um debate que possam iluminar a produção de um novo saber sobre o objeto (Caon, 1998). Todavia, é preciso que realizemos algumas digressões fundamentais para o entendimento da transdisciplinaridade.

Segundo Japiassu (1976), é necessário precisar o sentido da "disciplinaridade", examinando, em primeiro lugar, o que vem a ser uma "disciplina". Para o autor, é necessário que façamos

... certas precisões de ordem epistemológica nesses termos para chegarmos a uma diferenciação dos diversos tipos ou modalidades do "interdisciplinar". Assim, para nós, "disciplina" tem o mesmo sentido que "ciência". E "disciplinaridade" significa a exploração científica especializada de determinado domínio homogêneo de estudo, isto é, o conjunto sistemático e organizado de conhecimentos que apresentam características próprias nos planos de ensino, da formação, dos métodos e das matérias; esta exploração consiste em fazer surgir novos conhecimentos que se substituem aos antigos (p. 72).

Identificar disciplina com ciência é algo útil, mas ao mesmo tempo problemático. Fazer equivaler disciplina e ciência serve, com propriedade, à finalidade de uma definição operacional para o termo disciplinaridade. Entretanto é preciso lembrar o seguinte: toda ciência é uma disciplina, mas nem toda disciplina é uma ciência. Vejamos, então, como se organizam os níveis de agrupamento disciplinar (multi, pluri, inter e transdisciplinaridade) na visão de Japiassu (1976).

O primeiro nível é o da multidisciplinaridade. Sua descrição geral evoca uma gama de disciplinas propostas simultaneamente, mas sem fazer aparecer as relações que podem existir entre elas. É um tipo de sistema de um só nível e de objetivos múltiplos; não há nenhuma cooperação entre as disciplinas. Podemos pensar no seguinte exemplo: um hospital. Vários profissionais estão reunidos, mas trabalham isoladamente. O paciente realiza uma contagem de linfócitos, em seguida é atendido pelo oncologista e, finalmente, dirige-se à sala de quimioterapia. Neste caso não há contato entre os profissionais envolvidos no atendimento: o bioquímico da contagem de linfócitos, o médico oncologista e a enfermeira que cuida da quimioterapia não estão articulados entre si.

O segundo nível é a pluridisciplinaridade. Sua descrição geral envolve a justaposição de diversas disciplinas situadas, geralmente, no mesmo nível hierárquico e agrupadas de modo a fazer aparecer as relações existentes entre elas. É um tipo de sistema de um só nível e de objetivos múltiplos; há cooperação, mas sem coordenação. Exemplo sugerido: um paciente procura atendimento psiquiátrico e, após receber orientação e prescrição psicofarmacológica, é encaminhado, pelo próprio psiquiatra, a um psicólogo para um trabalho de psicoterapia. Os profissionais cooperam, mas não se articulam de maneira coordenada. 


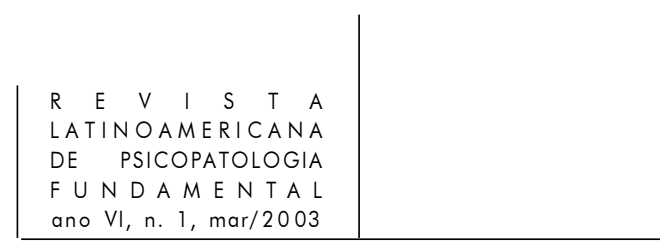

$\mathrm{Na}$ interdisciplinaridade, a descrição geral envolve uma axiomática comum a um grupo de disciplinas conexas e definidas no nível hierárquico imediatamente superior, o que introduz a noção de finalidade. É um tipo de sistema de dois níveis e de objetivos múltiplos com a coordenação procedendo de nível superior. Exemplo sugerido: uma equipe de atendimento ambulatorial de gestantes adolescentes de baixa renda. A equipe é formada por um médico pediatra, um médico psiquiatra, um psicólogo, um assistente social, um psicopedagogo, uma enfermeira e uma secretária. Cada área mencionada agrega ainda estudantes que realizam estágio no ambulatório. Todavia, o que prevalece é o saber médico, cabendo a coordenação e a tomada de decisão aos profissionais da área médica que dirigem e orientam a equipe em seu trabalho.

$\mathrm{Na}$ transdisciplinaridade, a descrição geral envolve uma coordenação de todas as disciplinas e interdisciplinas em um sistema de ensino inovado sobre a base de uma axiomática geral. É um tipo de sistema de níveis e objetivos múltiplos. A coordenação propõe uma finalidade comum dos sistemas. Exemplo: numa equipe de posto de saúde encontramos diversos profissionais reunidos. Pensemos na equipe que recebe pacientes com problemas mentais. Esta equipe, muito provavelmente, congregará profissionais como psicólogos, psiquiatras, enfermeiros, assistentes sociais, fonaudiólogos, fisioterapeutas, neurologistas, clínicos gerais, etc. É verdade que muitas vezes não encontraremos todos esses profissionais, porém, via de regra, boa parte deles formam uma equipe de trabalho na área de saúde mental. Quando o paciente chega para uma avaliação todos irão assisti-lo e buscarão formular um diagnóstico acerca do caso. Para que esse diagnóstico seja dado em situação de transdisciplinaridade não basta apenas que cada profissional opine a partir de sua área e no final das contas um tratamento seja indicado. Isso é ponto pacífico. Para que a configuração transdisciplinar seja alcançada é preciso que esses profissionais, fundamentalmente, estejam reciprocamente situados em sua área de origem e na área de cada um dos colegas. Isso pode parecer simples, mas não é. Para que a configuração transdisciplinar se torne verdadeira é necessário que o psicólogo, por exemplo, seja introduzido na área de seu colega assistente social e na área de seu colega psiquiatra e viceversa. Ademais, é necessário que cada problema não solucionado em uma das áreas seja levado para uma área vizinha e, assim, seja submetido à luz de um novo entendimento. Quando, hipoteticamente, um psicólogo percebe a insuficiência de seus paradigmas no trabalho com o autismo, ele poderá propor ao seu colega neurologista um desafio: que ali onde a psicologia não consegue formular uma intervenção (e o que resulta disso é uma interrogação), a neurologia possa, talvez e com a ajuda das demais áreas que compõem a equipe, iluminar o caminho com alguma proposta de intervenção. Esta é a situação paradigmática para geração de novos dispositivos para o trabalho com o autismo, por exemplo. 


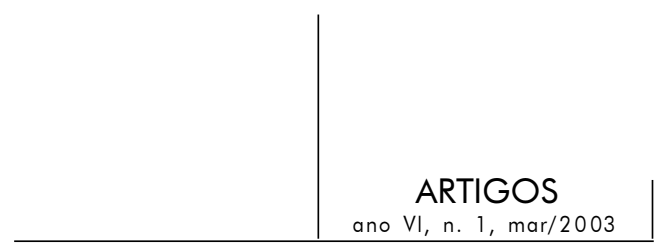

Todavia, é necessário que psicólogo e neurologista se coloquem humildemente à disposição um do outro e do caso, evitando demorar-se na comum posição de discutir algumas incompatibilidades que podem surgir entre as duas áreas. Nosso exemplo apresenta dois profissionais apenas, mas é importante salientar que isso vale para todos os encontros possíveis entre as áreas que compõem uma equipe de trabalho com saúde mental.

Para complementar nossa exposição sobre a transdisciplinaridade, evocaremos os trabalhos de Piaget (1972, apud Japiassu, 1976) e de Caon (1994). A visão piagetiana trazida por Japiassu, longe de representar um exagero na diversidade epistemológica de nossa proposição, ou mesmo de revelar incompatibilidade, demonstra, por si mesma, o quanto é necessário difundir o espírito transdisciplinar - a ser começado justamente por nossa proposição de um diagnóstico transdisciplinar:

Enfim, à etapa das relações interdisciplinares, podemos esperar que se suceda uma etapa superior, que não se contentaria em atingir interações ou reciprocidade entre pesquisas especializadas, mas que situaria essas ligações no interior de um sistema total, sem fronteiras estabelecidas entre as disciplinas. (p. 75)

Nossa proposição busca oportunizar essa discussão, e entende a transdisciplinaridade como um desafio colocado pelo interesse de uma equipe de profissionais que estão reunidos pela metáfora proposta por Caon (1997):

... em transdisciplinaridade, cada pesquisador problematiza os conceitos de diferentes campos: um entra na disciplina e olha pela luneta do outro pesquisador, interroga os dispositivos práticos e teóricos com os quais o primeiro pesquisador anfitrião vê aquilo que diz ver. (...) Na transdisciplinaridade, os dispositivos destinados à equação e solução do problema são mais importantes do que a solução da mesma. (p. 24)

\section{Meditações preliminares acerca dos princípios práticos do DTP}

A origem do DTP está situada no trabalho de equipe. Independente da modalidade - pluri, multi, inter ou transdisciplinar -, o que é vital para uma formulação originária do diagnóstico transdisciplinar em psicopatologia é a reunião de diversos profissionais em um trabalho integrado de equipe. Mas não basta apenas uma equipe coordenada, colaborativa e com uma finalidade. É preciso que haja algo mais. É preciso que haja um compromisso com a geração de dispositivos renovados para o trabalho com o psicopatológico. É necessário também que cada membro da equipe esteja o mais familiarizado possível com a 


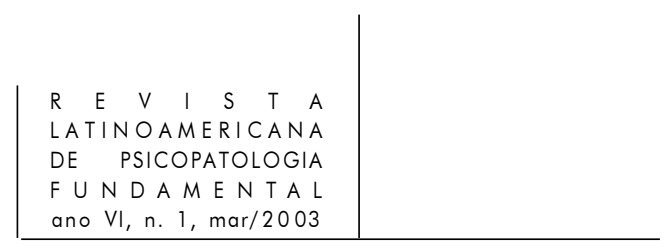

diversidade de disciplinas e que freqüente continuamente as casas das disciplinas de seus colegas. Ademais, é preciso ainda que os discursos se tornem legíveis e não mais exercícios velados e obscuros. Uma questão psicofarmacológica complexa deverá ser exposta com a mesma clareza que uma orientação diagnóstica do serviço social, por exemplo. Isso nos permite entrever a necessidade do abandono do jargão com que cada disciplina institui seu saber. A comunicação entre os membros da equipe, portanto, não seguirá mais um modelo verticalizado, baseado na liderança de um saber sobre outro(s), mas deverá assumir uma característica horizontal, onde todos, igualmente, compartilham de seus conhecimentos e saberes. Dessa maneira, a tomada de decisão em relação ao que está sendo discutido será uma tomada de decisão horizontal, onde não há prevalência de um saber sobre outro ou sobre os demais. Assim sendo, de maneira breve, podemos enumerar aqui os cinco princípios práticos do DTP: trabalho em equipe; geração de novos dispositivos; familiarização dos profissionais com cada área diferente da sua; legibilidade e compartilhamento dos discursos e tomada de decisão horizontal.

\section{O trabalho em equipe}

Uma equipe será transdisciplinar quando sua reunião congregar diversas especialidades com a finalidade de uma cooperação entre elas sem que uma coordenação se estabeleça a partir de um lugar fixo. É claro que isso gera, de saída, um problema. Como evitar a verticalidade de uma coordenação? Isto é, como evitar que uma especialidade se torne uma espécie de juiz no processo de tomada de decisão? Ora, a transdisciplinaridade deve ser encarada como meta a ser alcançada e nunca como algo pronto, como um modelo aplicável e um desafio que serve de parâmetro para que todos os membros da equipe estejam atentos para eventuais cristalizações e centralizações do poder.

Por exemplo, numa equipe de unidade psiquiátrica é muito comum observarmos um funcionamento bastante integrado, interdisciplinar. Mas qual é a barreira que encontramos aí para que a transdisciplinaridade floresça? É comum observar no trabalho das equipes a presença de técnicos mais antigos, que estão há mais tempo na equipe, e que, por isso, estão mais investidos de uma transferência de trabalho. Esse investimento transferencial por parte dos colegas gera, espontaneamente, um lugar de liderança para o técnico em questão. Algumas vezes, é verdade, seu trabalho é realmente mais pontual, mais antigo, o que lhe dá mesmo condições de tomar boas decisões ou influenciar seus colegas na tomada de uma decisão adequada. Outras vezes, no entanto, o técnico mais antigo sofre das mes- 


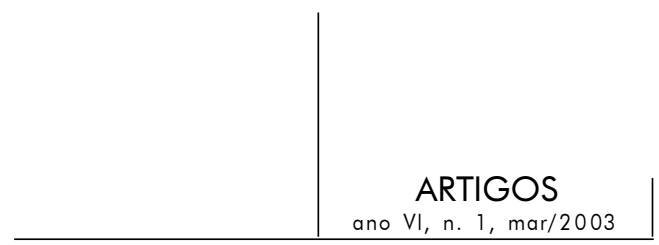

mas inseguranças que os colegas de menor tempo na equipe. É muito comum acontecer de o técnico tratado como líder encontrar embaraço em compartilhar suas dificuldades, pois teme decepcionar seus colegas. Há ainda a questão de uma liderança necessária. É o caso do chefe de equipe. O chefe de equipe, investido ou não pela transferência de trabalho, ocupa o lugar de líder e isso pode trazer consequiências de diversas naturezas. Entre elas, talvez as principais e mais comuns, estão o exercício vaidoso da liderança e o conflito natural que as diferenças pessoais e profissionais entre os membros acarretam. Por isso tudo é que a transdisciplinaridade, mais que um perfil ideal, é uma meta que a equipe deverá estabelecer para poder viver um permanente processo de avaliação de seu próprio trabalho nas diferentes perspectivas que a atravessam. Mas é importante lembrar: não queremos dizer que as lideranças e as chefias de equipe são totalmente nocivas. Desejamos, acima de tudo, chamar a atenção para a necessidade destas lideranças e chefias buscarem incessantes questionamentos acerca de suas posições e estimularem o debate entre os demais membros da equipe. Exemplo sugerido: muitas vezes, o estagiário que chega recebe, na equipe, um lugar fixado. É o lugar de quem deve aprender, certamente, mas não deixa de significar um olhar novo, estrangeiro, de quem chega e pode vislumbrar as coisas com algumas sutilezas que muitas vezes escapam aos profissionais mais antigos. Podemos sugerir, ainda, o exemplo daquela equipe que cria e sustenta um imaginário onde uma determinada especialidade é portadora de uma voz que ensurdece as outras especialidades. Assim sendo, toda a equipe abre mão de seus discursos singulares para fazer coro com aquela especialidade que está mais investida de transferência - como vimos acima na chamada transferência de trabalho. O trabalho em equipe numa perspectiva transdisciplinar requer humildade e disponibilidade por parte de cada profissional, pois é, em suma, um movimento de reconhecimento da posição do outro em relação a mim e de mim em relação ao outro. Mas como dissemos: movimento de reconhecimento e não o triste desreconhecimento que muitas vezes é observado na relação entre alguns profissionais que se ignoram e não sabem que com isso quem perde é o paciente.

\section{A geração de novos dispositivos}

Gerar novos dispositivos é a segunda meta a que uma equipe transdisciplinar deve se inclinar. Mas o que são novos dispositivos? Novos dispositivos são conhecimentos que resultam de uma discussão compartilhada acerca do problema que exige solução. Muitas vezes, o novo dispositivo não é a solução, mas um passo fundamental para que se possa encontrá-la. O mais importante para a 


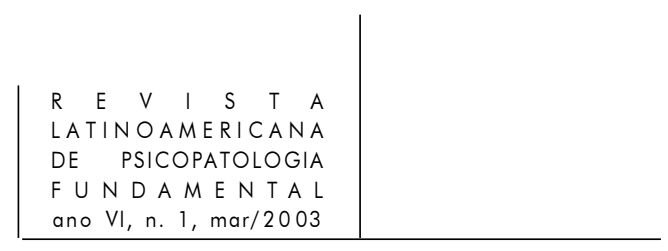

geração de novos dispositivos é que os profissionais possam se ajudar reciprocamente. Exemplo sugerido: para que um novo dispositivo encontre lugar, é preciso, primeiro, muita humildade e reconhecimento de dificuldades insolúveis no campo em que o problema se origina. Quando um profissional falha em sua intervenção ou sequer consegue formulá-la, este é o momento ideal para que um novo dispositivo possa ser gerado. Mas de que forma? Ora, cabe ao profissional levar seu problema a casa de uma especialidade vizinha (ou de várias) e esperar que o problema, até então insolúvel em sua área, seja examinado e colocado sob o foco de outras intervenções. Assim, uma troca de informações será estimulada e aquilo que uma determinada área tem como insolúvel poderá revelar detalhes ainda não percebidos. Muitos de nós já ouvimos falar de casos em que um assistente social, por exemplo, pôde ajudar seu colega médico e seu colega psicólogo com informações que muitas vezes não aparecem no setting de trabalho clínico, ficando desconhecidas enquanto pérolas valiosas nas entrevistas de triagem.

\section{Familiarização dos profissionais com cada área diferente da sua}

Quando profissionais de diferentes áreas estão reunidos em equipe é preciso que estejam familiarizados com as diferenças entre eles e suas respectivas áreas de conhecimento. Mas não estamos falando de uma familiarização superficial. É preciso que cada profissional descubra um interesse e uma curiosidade pela área de seu colega. Exemplo sugerido: quando uma equipe está reunida e deseja optar por um funcionamento transdisciplinar é necessário que cada membro exponha suas ferramentas de trabalho, suas teorias, seu entendimento do caso e, sobretudo, cobre de seu colega a mesma exposição. Mas tais exposições não podem ser esotéricas, herméticas, pois o objetivo é que os discursos sejam compartilhados e para isso acontecer é preciso que estes sejam, em primeira instância, acessíveis e legíveis, de modo que produzam ressonâncias naqueles que os recebem. O que nos leva à necessidade de uma legibilidade dos discursos.

\section{Legibilidade e compartilhamento dos discursos}

Para que o intercâmbio entre os profissionais da equipe seja também de caráter transdisciplinar, é preciso que os discursos - técnicos e ligados ao chamado jargão de cada área - sejam compartilhados. Porém não basta apenas 


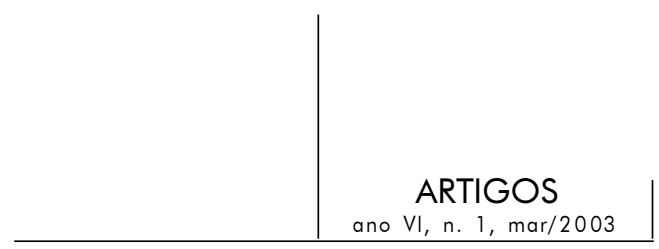

levar ao colega aquelas palavras que em nosso campo são elementares. É preciso realizar um cuidadoso trabalho de tradução e explicação do que se deseja dizer em cada discurso de cada área. É preciso que o discurso seja legível, que o outro que me escuta entenda, em termos claros e objetivos, portanto distante de qualquer discurso técnico, o que eu desejo apresentar sobre a conduta de determinado paciente, por exemplo. Numa equipe que busca um diagnóstico transdisciplinar, os discursos têm de ser inteligíveis para todos.

\section{Tomada de decisão horizontal}

A tomada de decisão é o aspecto culminante de uma orientação diagnóstica transdisciplinar para o psicopatológico. Para que uma direção de tratamento seja estabelecida é preciso que a decisão seja tomada sem que nenhum saber prevaleça sobre outro, por isso a necessidade de ser horizontal, numa linha em que todos os profissionais estejam reunidos e dêem a sua contribuição de maneira compartilhada. Na verdade, a tomada de decisão está ligada a um conjunto de decisões que emanam de todas as áreas implicadas no trabalho em equipe. Não se trata do que cada área acredita ser adequado para o caso, mas sim daquilo que o próprio caso (paciente) irá demonstrar como urgente e necessário para o seu tratamento.

\section{Considerações finais e provisórias}

Como foi anunciado no início do trabalho, o objetivo era o de apresentar considerações preliminares acerca de uma pesquisa em andamento sobre o DTP. A partir delas, o autor espera ter contribuído para o incentivo das iniciativas que provavelmente já se observam nos trabalhos com a clínica da psicose na rede de saúde pública. No entanto, esse artigo serve também como registro de uma tentativa de sistematização do DTP. Essa sistematização é tema e objetivo das pesquisas que o autor vêm realizando, e suas ilustrações serão o propósito de um próximo artigo sobre o DTP. O objetivo maior do DTP, no entanto, é o alcance de um discurso renovado sobre o psicopatológico. Um discurso produzido em situação de transdisciplinaridade e que visa promover um diálogo entre diferentes áreas do conhecimento e seus dispositivos clínicos. O diálogo serve como ensejo para uma situação de cooperação entre as diferentes áreas. Transdisciplinaridade é diálogo e cooperação. 


\section{Referências}

Bastos, A. O psicótico da apresentação de doentes. Tecendo Saberes - Jornada de Pesquisadores em Ciências Humanas (Edição dos 230 trabalhos selecionados da III, IV e V Jornadas de Pesquisadores em Ciências Humanas, realizadas em 1996, 1997 e 1999 no CFCH da Universidade Federal do Rio de Janeiro). CD-ROM

Berlinck, M. T. Psicopatologia Fundamental. São Paulo: Escuta, 2000.

Boss, M. Angústia, culpa e libertação. São Paulo: Livraria Duas Cidades, 1975.

CAON, J. L. O pesquisador psicanalítico e a situação psicanalítica de pesquisa. Psicologia: reflexão e crítica, v. 7, n. 2, p. 145-74, 1994.

Da existência analfabética à existência analfabetizada. Revista do GEEMPA, n. 6, p. 37-70, 1998.

DoR, J. Estrutura e perversão. Porto Alegre: Artes Médicas, 1991.

DSM-IV. Critérios diagnósticos. Porto Alegre: Artes Médicas, 1995.

Ey, H., Bernard, P. e Brisset, C. Manual de psiquiatria. Rio de Janeiro: MassonAtheneu, 1990.

GabBard, G. Psiquiatria psicodinâmica na prática clínica. Porto Alegre: Artes Médicas, 1990.

Gadamer, H. G. Verdade e método. Petrópolis: Vozes, 2000.

Garcia-RozA, L. A. Introdução à metapsicologia freudiana. Rio de Janeiro: Zahar, 1992. v. I.

HusSERL, E. Méditations cartésiennes: introduction a la phénoménologie. Paris: J. Vrin, 1960.

IRIBARRY, I. N. Ética, sublimação e aprendizagem heróica: os três eixos fundamentais da experiência de tratamento psicanalítico. Dissertação de Mestrado nãopublicada, Curso de Pós-Graduação em Psicologia do Desenvolvimento, Universidade Federal do Rio Grande do Sul, Porto Alegre, RS, 2000.

O diagnóstico transdisciplinar em psicopatologia (ensaios de Analítica Existencial, Metapsicologia e Apresentação Psicanalítica de Pacientes enquanto fundamentos de sua demonstração). Projeto de Doutorado nãopublicado, Curso de Pós-Graduação em Psicologia do Desenvolvimento, Universidade Federal do Rio Grande do Sul, Porto Alegre, RS, 2002.

JAPIASSU, H. Interdisciplinaridade e patologia do saber. Rio de Janeiro: Imago, 1976.

LACAN, J. Escritos. Rio de Janeiro: Zahar, 1998.

Nicolescu, B. La transdisciplinarité, manifeste. Paris: Éditions du Rocher, 1996.

Platão. O banquete. São Paulo: Martin Claret, 2001.

Ricoeur, P. Tempo e narrativa. Campinas: Papirus, 1990. Tomo I. 


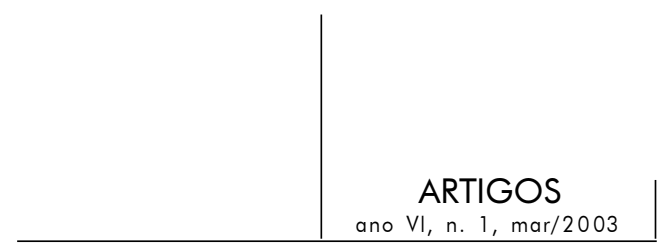

Resumos

Este artículo es una presentación del Diagnóstico Transdisciplinario en Psicopatología (DTP). El DTP es un dispositivo cuyo propósito es motivar y sistematizar el acercamiento y el diálogo entre psiquiatría y psicoanálisis. El DTP pretende conjugar los esfuerzos de los dispositivos técnicos de la psiquiatría y del psicoanálisis. Tales dispositivos (la presentación psiquiátrica de pacientes, DSM-IV, presentación psicoanalítica de pacientes y escucha psicoanalítica) son colocados en una situación de diálogo y colaboración para llevar a cabo la aplicación del DTP.

Palabras clave: Diagnóstico, transdisciplinar, psicopatología

Cet article se présente comme une préface du Diagnostique Transdisciplinaire en Psychopathologie (DTP). Le DTP est un dispositif dont la finalité vise à inciter et à systématiser l'approche et le dialogue entre la psychiatrie et la psychanalyse. Le DTP prétend conjuguer les efforts dispositifs techniques de la psychiatrie et de la psychanalyse (la présentation psychiatrique de pacients, le DSM-IV, la présentation et l'écoute psychanalytique de patients). Tout ces dispositifs sont présentés de façon à favoriser le dialogue et la coopération pour l'application du DTP.

Mots clés: Diagnostique, transdisciplinaire, psychopathologie

This article consists of a preliminary presentation of Transdisciplinary Diagnosis in Psychopathology (TDP). TDP consists of an approach aimed at fostering and systematising the approximation and dialogue between psychiatry and psychoanalysis. TDP is a step toward joining psychiatric and psychoanalytical technical tools. Such tools (such as the psychiatric presentation of patients, DSM-IV, the psychoanalytic presentation of patients, and psychoanalytic listening) are placed together in transdisciplinarity and mutual co-operation, in order to broaden the possibilities for diagnosis in the clinic of psychosis.

Key words: Diagnosis, transdisciplinarity, psychopathology

Versão inicial recebida em setembro de 2002

Versão revisada recebida em fevereiro de 2003 